\title{
Well Performance Simulation and Parametric Study for Different Refracturing Scenarios in Shale Reservoir
}

\author{
Jing Huang $\mathbb{D}^{1}{ }^{1}$ Lan Ren, ${ }^{1}$ Jinzhou Zhao $\mathbb{D}^{1},{ }^{1}$ Zhiqiang ${ }^{2}{ }^{2}$ and Junli Wang ${ }^{3}$ \\ ${ }^{1}$ State Key Laboratory of Oil and Gas Reservoir Geology and Exploitation, Southwest Petroleum University, Chengdu, \\ Sichuan 610500, China \\ ${ }^{2}$ School of Petroleum and Natural Gas Engineering, Chongqing University of Science and Technology, Chongqing 401331, China \\ ${ }^{3}$ Shu'nan Gas-Mine Field, PetroChina Southwest Oil and Gas Field Company, Luzhou, Sichuan 646000, China
}

Correspondence should be addressed to Jing Huang; huangjing_swpi@163.com and Jinzhou Zhao; zhaojz@swpu.edu.cn

Received 8 May 2018; Revised 6 July 2018; Accepted 17 July 2018; Published 23 August 2018

Academic Editor: Mandadige S. A. Perera

Copyright (C) 2018 Jing Huang et al. This is an open access article distributed under the Creative Commons Attribution License, which permits unrestricted use, distribution, and reproduction in any medium, provided the original work is properly cited.

\begin{abstract}
Refracturing is an encouraging way to uplift gas flow rate and ultimate gas recovery from shale gas wells. A numerical model, considering the stimulated reservoir volume and multiscale gas transport, is applied to simulate the gas production from a refractured shale gas well. The model is verified against field data from a shale gas reservoir in Sichuan Basin. Two refracturing scenarios: refracturing through existing perforation clusters and refracturing through new perforation zones, are included in the simulation work. Three years after production is determined to be the optimum time for refracturing based on the evolution analysis of reservoir pressure, effective stress, fracture permeability, and gas recovery. The role that the hydraulic fracture conductivity and hydraulic fracture half-length play in gas production for different refracturing cases is explored. Pumping parameters of the refracturing job in Sichuan Basin are discussed combining with sensitivity analysis, and suggestions for pumping parameters optimization are proposed.
\end{abstract}

\section{Introduction}

The gas flow rate of shale wells declines significantly in the very first years after the initial hydraulic stimulation, and the large volume of gas still remains in a shale reservoir [1]. Some wells might not achieve an economical gas flow rate when the initial stimulation is inadequate: small treatment size, low proppant concentration, poor proppant distribution, poor fracturing fluid selection, insufficient perforations, and operational problems with completion [2-7]. Refracturing is an encouraging way to uplift shale reservoir gas production and ultimate gas recovery by enlarging fracture geometry, creating new fractures, improving pay coverage, reinflating natural fractures, increasing proppant conductivity, and restoring fracture conductivity [8-11]. Compared to drilling and completing of infill wells, refracturing is an economical alternative to promote well productivity when the right candidate is selected [12-16]. The refracturing process has been developed and applied to Barnett, Haynesville,
Bakken, Fayetteville, Eagle Ford, and Woodford shale reservoirs in recent years $[6,15]$.

Gas flow from an ultralow permeability shale reservoir through a complex fracture network, stress, and pressure field change must be modeled so that restimulation designs and completion strategies can be properly evaluated. It is difficult to predict gas production and improvement in hydrocarbon recovery post refracturing treatment. Several previous works developed numerical simulation approaches to model fluid flow, complex fracture networks, and initial hydraulic fractures of refracturing treatment. Tavassoli et al. perform a sensitivity study on the effect of different reservoir and hydraulic fracture parameters on refracturing performance based on a dual permeability model [11]. Rodvelt et al. use an analytical production simulator to forecast the productivity index and EUR of Marcellus shale wells [8]. Haddad et al. use commercial software program to simulate the gas production of a refractured shale reservoir [16]. Urban et al. use a dual permeability simulator that takes into 
account free gas in matrix and fractures and adsorbed gas to simulate refracturing in the Eagle Ford shale [17]. Huang et al. use a finite element method to evaluate the well performance under different refracturing designs [18]. However, these models are still not applicable to describe the complex gas flow transport mechanism in shale gas reservoirs due to the different sorption behavior and flow regimes between kerogen pockets and the inorganic solid medium.

In this paper, a numerical model, considering the stimulated reservoir volume and multiscale gas transport, is applied to simulate the gas production from a refractured shale gas well. The model is verified against field data of a refractured shale horizontal well in Sichuan Basin, Southwest of China. The evolution of effective stress, reservoir pressure, fracture permeability, and gas recovery is analyzed to determine the optimum time for refracturing. Two refracturing scenarios: refracturing through existing perforation clusters and refracturing through new perforation zones, are included in the simulation work. The role that the hydraulic fracture conductivity and hydraulic fracture half-length play in gas production for different refracturing cases is explored. In addition, the pumping parameters of the refracturing job are discussed combined with sensitivity analysis.

\section{Governing Equations}

A shale reservoir is a triple-continuum formation which consists of organic matter, inorganic matrix, and natural fractures [19]. During the production process, the gas release follows the mechanism: kerogen system-inorganic matrix system-fracture system [20]. The effective stress increases while the reservoir pressure depletes, in which, in turn, the porosity and permeability of shale reservoir change due to rock matrix deformation. The stress sensitivity will further reduce the flow capacity of the fracture system in the stimulated area [21], which is a critical factor for production prediction and optimal designation of restimulation. The existing complex fracture network is properly characterized in this numerical model; in addition, the solid deformation effect and complex gas flow behavior are taken into consideration. Sang et al. presented the model assumptions [22].

\subsection{Deformation of Fractured Porous Shale}

2.1.1. Constitutive Equation. Considering the kerogen matrix, inorganic matrix, and fractured solid system as linearly elastic media, the constitutive equation for fractured porous shale can be generally expressed as

$$
G \nabla^{2} u+(G+\lambda) \nabla \varepsilon_{\mathrm{v}}-\left(\frac{2 G}{3}+\lambda\right) \nabla \varepsilon_{\mathrm{S}}-\left(\alpha_{\mathrm{m}} \nabla P_{\mathrm{m}}+\alpha_{\mathrm{k}} \nabla P_{\mathrm{k}+} \alpha_{\mathrm{f}} \nabla P_{\mathrm{f}}\right)=0
$$

2.1.2. Initial and Boundary Conditions. Assuming that the well is not disturbed under the original geological state, therefore, the displacement of shale rock is zero and the initial condition can be presented as

$$
\begin{aligned}
& u_{x}(x, y, t)=0, \\
& u_{y}(x, y, t)=0 .
\end{aligned}
$$

The boundary conditions can be presented as

$$
\begin{aligned}
& \left.u_{x}\right|_{x=0}=0\left(y=0 \sim Y_{e}\right), \\
& \left.u_{x}\right|_{x=X_{e}}=0\left(y=0 \sim Y_{e}\right), \\
& \left.u_{y}\right|_{x=0}=0\left(y=0 \sim Y_{e}\right), \\
& \left.u_{y}\right|_{x=X_{e}}=0\left(y=0 \sim Y_{e}\right), \\
& \left.u_{x}\right|_{y=0}=0\left(x=0 \sim Y_{e}\right), \\
& \left.u_{x}\right|_{y=Y_{e}}=0\left(y=0 \sim X_{e}\right), \\
& \left.u_{y}\right|_{y=0}=0\left(x=0 \sim Y_{e}\right), \\
& \left.u_{y}\right|_{y=Y_{e}}=0\left(y=0 \sim X_{e}\right) .
\end{aligned}
$$

2.2. Stress-Dependent Porosity and Permeability. The effective pressure of triple-continuum formation can be presented as [23]

$$
\sigma_{i j}^{\prime}=\sigma_{i j}-\left(\alpha_{\mathrm{m}} P_{\mathrm{m}}+\alpha_{\mathrm{k}} P_{\mathrm{k}}+\alpha_{\mathrm{f}} P_{\mathrm{f}}\right) \delta_{i j}
$$

Stress-dependent correlations are used to consider porosity and permeability reduction. Based on experimental and numerical simulation results [24], power law correlations are used to calculate these stress-dependent properties as follows:

$$
\begin{gathered}
\phi_{\xi}=\phi_{\xi 0} \exp \left(-c_{\xi}\left(\sigma^{\prime}-\sigma_{0}^{\prime}\right)\right), \\
K_{\xi}=K_{\xi 0} \exp \left(-c_{\xi}\left(\sigma^{\prime}-\sigma_{0}^{\prime}\right)\right) .
\end{gathered}
$$

\subsection{Gas Flow}

2.3.1. Continuity Equation of Kerogen System. The transport mechanisms in the kerogen system include viscous flow, Knudsen diffusion, and surface diffusion. Regardless of the space transmission of the gas in kerogen, the continuity equation of the kerogen system can be present as

$$
-\frac{\sigma_{\mathrm{km}} \rho_{\mathrm{g}} K_{\mathrm{kapp}}\left(P_{\mathrm{k}}-P_{\mathrm{m}}\right)}{\mu_{\mathrm{g}}}=\frac{\partial\left(\varepsilon_{\mathrm{kp}} \phi \rho_{\mathrm{g}}\right)}{\partial t}+\frac{\partial\left[\varepsilon_{\mathrm{ks}}\left(1-\phi_{\mathrm{m}}-\phi_{\mathrm{f}}\right) q_{\mathrm{a}}\right]}{\partial t},
$$

where $q_{\mathrm{a}}$ is the adsorbed gas volume per unit volume kerogen and defined as

$$
q_{a}=\frac{\rho_{s} V_{L} M_{g}}{V_{s t d}} \frac{P_{k}}{P_{L}+P_{k}},
$$

where $K_{\text {kapp }}$ is the apparent kerogen permeability and defined as

$$
K_{\mathrm{kapp}}=K_{\mathrm{k} 0}+\frac{\varepsilon_{\mathrm{kp}} \phi D_{\mathrm{kk}} \mu_{\mathrm{g}}}{C_{\mathrm{k}} Z R_{\mathrm{g}} T}+\frac{\varepsilon_{\mathrm{ks}}\left(1-\phi_{\mathrm{m}}-\phi_{\mathrm{f}}\right) D_{\mathrm{s}} C_{\mu \mathrm{s}} \mu_{\mathrm{g}} P_{\mathrm{k}}}{\left(P_{\mathrm{L}}+P_{\mathrm{k}}\right)^{2} C_{\mathrm{k}}},
$$


where $D_{\mathrm{kk}}$ is Knudsen diffusivity of the kerogen system and defined as

$$
D_{\mathrm{kk}}=\frac{\phi_{\mathrm{k}}}{\tau} \frac{2 r_{\mathrm{k}}}{3}\left(\frac{8 R T}{\pi M_{\mathrm{g}}}\right)^{1 / 2} .
$$

2.3.2. Continuity Equation of Inorganic Matrix System. The free gas transport in an inorganic matrix involves two transfer terms. On the one hand, the adsorbed gas diffuses from the kerogen system to the inorganic matrix system. On the other hand, the inorganic matrix system supplies gas for the fracture system. Considering the slippage effect, Knudsen diffusion, and viscous flow, the gas continuity equation of the inorganic matrix system can be presented as

$$
\nabla \cdot\left(\frac{\rho_{\mathrm{g}} K_{\mathrm{mapp}}}{\mu_{\mathrm{g}}} \nabla P_{\mathrm{m}}\right)+W_{\mathrm{km}}-W_{\mathrm{mf}}=\frac{\partial\left[\left(1-\varepsilon_{\mathrm{kp}}\right) \phi \rho_{\mathrm{g}}\right]}{\partial t},
$$

where $K_{\text {mapp }}$ is the apparent inorganic matrix permeability and defined as

$$
K_{\text {mapp }}=\frac{\phi_{\mathrm{m}}\left(1-\varepsilon_{\mathrm{kp}}\right)}{\tau}\left(D_{\mathrm{km}} \mu_{\mathrm{g}} C_{\mathrm{g}}+F_{\mathrm{m}} \frac{r_{\mathrm{m}}^{2}}{8}\right)
$$

where $F_{\mathrm{m}}$ is the slippage factor and defined as

$$
F_{\mathrm{m}}=1+\frac{\mu_{\mathrm{g}}}{P_{\mathrm{m}} r_{\mathrm{m}}}\left(\frac{2}{\alpha}-1\right)\left(\frac{8 \pi R T}{M_{\mathrm{g}}}\right) 0.5,
$$

where $D_{\mathrm{km}}$ is the Knudsen diffusivity of the inorganic matrix system and can be defined as

$$
D_{\mathrm{km}}=\left(\frac{2 r_{\mathrm{m}}}{3}\right)\left(\frac{8 R T}{\pi M_{\mathrm{g}}}\right) 0.5,
$$

where $W_{\mathrm{mf}}$ is the transfer term between the inorganic matrix system and fractures. It can be presented based on the Warren-Root transfer model:

$$
W_{\mathrm{mf}}=\frac{\sigma_{\mathrm{mf}} \rho_{\mathrm{g}} K_{\text {mapp }}\left(P_{\mathrm{m}}-P_{\mathrm{f}}\right)}{\mu_{\mathrm{g}}},
$$

where $\sigma_{\mathrm{mf}}$ is the pseudosteady state shape factor, which can be defined as [25]

$$
\sigma_{\mathrm{mf}}=4\left(\frac{1}{L_{\mathrm{fx}}^{2}}+\frac{1}{L_{\mathrm{fy}}^{2}}\right) .
$$

2.3.3. Continuity Equation of Fracture System. The pore diameters in the fracture system are equal to the millimeter scale, the Knudsen diffusion in the fracture system is notably small, and only viscous flow is taken into account. Therefore, according to the conservation of mass, the continuity equation of the fracture system can be present as

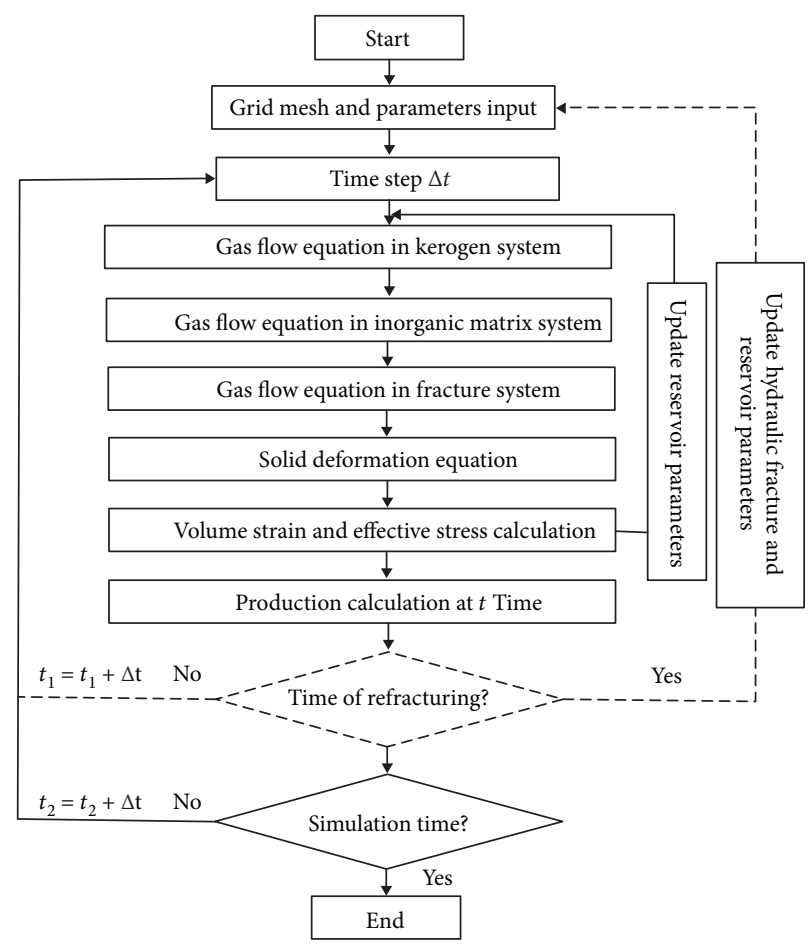

FIGURE 1: Simulation procedure of modeling initial fracturing and refracturing job.

$$
\nabla \cdot\left(\frac{\rho_{\mathrm{g}} K_{\mathrm{f}}}{\mu_{\mathrm{g}}} \nabla P_{\mathrm{f}}\right)+W_{\mathrm{mf}}-Q_{\mathrm{gwell}}=\frac{\partial\left(\rho_{\mathrm{g}} \phi_{\mathrm{f}}\right)}{\partial t},
$$

where $Q_{\mathrm{gwell}}$ is the production rate of the fracture system and can be defined based on the Peaceman model [26]:

$$
Q_{\mathrm{gwell}}=\frac{2 \pi \rho_{\mathrm{g}} K_{\mathrm{f}} W_{\mathrm{f}}}{\mu_{\mathrm{g}} V_{\mathrm{b}}} \frac{P_{\mathrm{f}}-P_{\mathrm{wf}}}{\ln \left(r_{\mathrm{e}} / r_{\mathrm{w}}\right)} .
$$

2.3.4. Initial and Boundary Conditions. Assuming that the initial pressures of the kerogen system, inorganic matrix system, and fracture system are identical, then the initial condition can be presented as

$$
\left.P_{\mathrm{k}}(x, y, t)\right|_{t=0}=\left.P_{\mathrm{m}}(x, y, t)\right|_{t=0}=\left.P_{\mathrm{f}}(x, y, t)\right|_{t=0}=P_{\mathrm{i}} .
$$

The shale formation is considered a closed unit. The bottom hole flow pressure is applied as the inner boundary condition:

$$
\left.\frac{\partial P_{\mathrm{f}}}{\partial n}\right|_{\Gamma_{1}}=P_{\mathrm{wf}} .
$$

The no-flow outer boundary condition is applied:

$$
\begin{gathered}
\left.\frac{\partial P_{\mathrm{f}}}{\partial n}\right|_{\Gamma_{0}}=0, \\
\left.\frac{\partial P_{\mathrm{m}}}{\partial n}\right|_{\Gamma_{0}}=0, \\
\left.\frac{\partial P_{\mathrm{k}}}{\partial n}\right|_{\Gamma_{0}}=0 .
\end{gathered}
$$


TABLE 1: Reservoir and wellbore geometry parameters for the simulation model.

\begin{tabular}{lccc}
\hline Parameter & Symbol & Value & Units \\
\hline Well radius & $r_{\mathrm{w}}$ & 0.1 & $\mathrm{~m}$ \\
Bottomhole flowing pressure & $P_{\mathrm{wf}}$ & 15 & $\mathrm{MPa}$ \\
Initial reservoir pressure & $P_{\mathrm{i}}$ & 20 & $\mathrm{MPa}$ \\
Transient shape factor & $\sigma_{\mathrm{km}}$ & 8 & $1 / \mathrm{m}^{2}$ \\
Pseudosteady state shape factor & $\sigma_{\mathrm{mf}}$ & $1 / \mathrm{m}^{2}$ \\
Initial porosity & $\phi_{\xi 0}$ & 1 & - \\
Natural fracture porosity & $\varphi_{\mathrm{f}}$ & - \\
Portion of kerogen grain volume in total shale core grain volume & $\varepsilon_{\mathrm{ks}}$ & 0.05 & - \\
Inorganic matrix permeability & $K_{\mathrm{mi}}$ & $\mu \mathrm{m}^{2}$ \\
Elastic modulus & $E$ & 0.1 & $\mathrm{GPa}$ \\
Poisson ratio & $v$ & $1 \times 10^{-7}$ & - \\
Initial conductivity of hydraulic fractures & $F_{\mathrm{cd}}$ & $\mathrm{D} \cdot \mathrm{cm}^{2}$ \\
Hydraulic fracture half-length & $L_{\mathrm{f}}$ & $\mathrm{m}$ \\
Maximum principal stress & $\sigma_{\mathrm{H}}$ & 0.2 & $\mathrm{MPa}$ \\
Minimum principal stress & $\sigma_{\mathrm{h}}$ & 0.1 & $\mathrm{MPa}$ \\
Reservoir thickness & $H$ & 70 & $\mathrm{~m}$ \\
Langmuir volume & $V_{\mathrm{L}}$ & 40 & $\mathrm{~m} / \mathrm{kg}$ \\
Langmuir pressure & $P_{\mathrm{L}}$ & 36 & $\mathrm{MPa}$ \\
Molecular mass & $M_{\mathrm{g}}$ & 50 & $\mathrm{~kg} / \mathrm{mol}$ \\
Surface diffusion coefficient & $D_{\mathrm{s}}$ & $\mathrm{m}{ }^{2} / \mathrm{s}$ \\
Length of horizontal well & $L$ & $\mathrm{~m}$ & $\mathrm{~m}$ \\
Reservoir temperature & $T$ & 6 & ${ }^{-3} \mathrm{C}$ \\
\hline
\end{tabular}

where $\Gamma_{1}$ represents the inner boundary of the production well and $\Gamma_{0}$ represents the outer boundary.

2.4. Simulation Procedure. The finite difference method is used to solve the highly nonlinear mathematical model. The simulation procedure is as follows:

Step 1. The stimulated area and hydraulic fractures are meshed by the nonuniform rectangular grid system.

Step 2. The pressure in the kerogen system, inorganic system, and fracture system is calculated, respectively.

Step 3. The pressure calculated in Step 2 is used to calculate the volume strain of grid points; after further calculating the average effective stress, the reservoir parameters are renewed and transferred to the gas flow model. The calculation pauses at the time for refracturing.

Step 4. Hydraulic fracture and reservoir parameters are updated at the time node of refracturing; the iterative computation will stop at the end of simulation time.

The simulation procedure detail is shown in Figure 1.

\section{Results and Discussion}

3.1. Model Validation against Field Data. A horizontal well with multistage hydraulic fracturing is placed in the center of the reservoir model $(500 \mathrm{~m} \times 400 \mathrm{~m} \times 50 \mathrm{~m})$. Reservoir and wellbore geometry parameters similar to shale gas field in Sichuan Basin, Southwest of China, are presented in Table $1.395 \mathrm{~m}$ of the horizontal wellbore was initially stimulated with 6 stages, and the horizontal well achieved an average daily gas flow rate of $2.5 \times 10^{4} \mathrm{~m}^{3}$ during the early production stage. However, the daily gas flow rate sharply declined to less than $0.5 \times 10^{4} \mathrm{~m}^{3}$ after 4 years of production; it cannot meet the critical liquid carrying flow, and the well was shut in.

The refracturing job of this well was carried out by general temporary plug and diversion process. The slick water was firstly pumped through the casing to compensate reservoir energy. While the bottom hole pressure (BHP) reached instantaneous shut-in pressure (ISIP) of the initial fracturing treatment, the particulate drops were pumped downhole to temporarily block open perforations, and the larger proppant mass treament schedules were further pumped. The increased pressure gained with particulate drops and stages of sand indicating diversion into new rock. The process was repeated for last 3 stages. The altered stress field leads to the main uncertainty of 


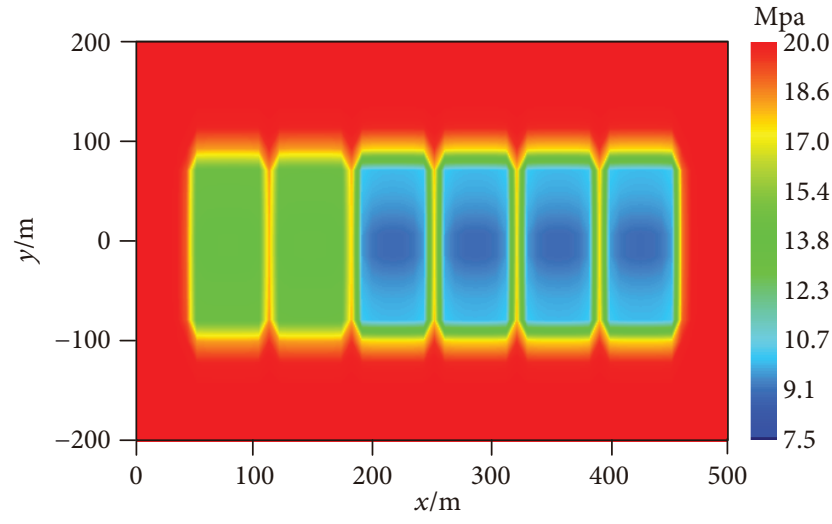

(a)

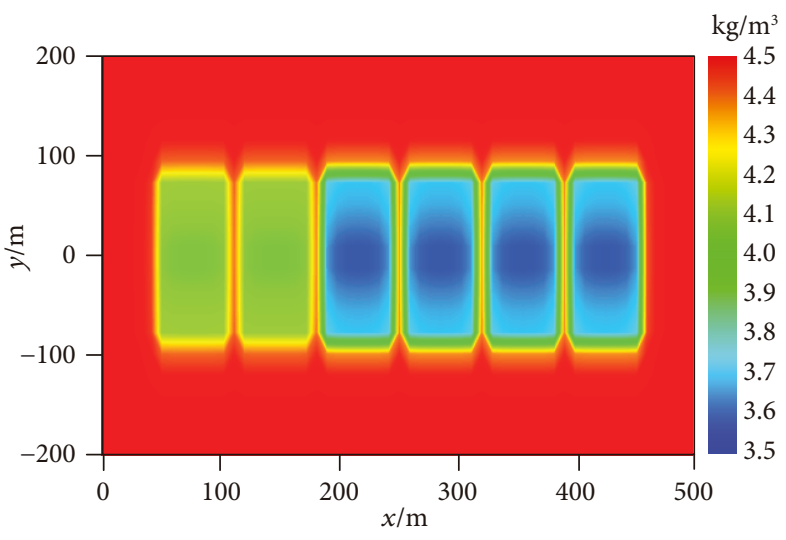

(b)

FIGURE 2: Reservoir pressure and reservoir adsorption gas content distribution after refracturing treatment.

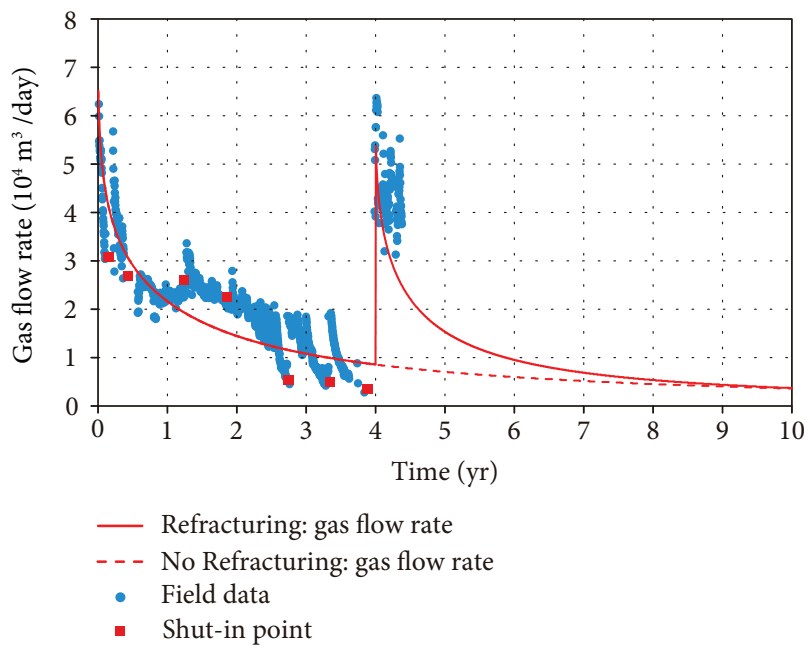

(a)

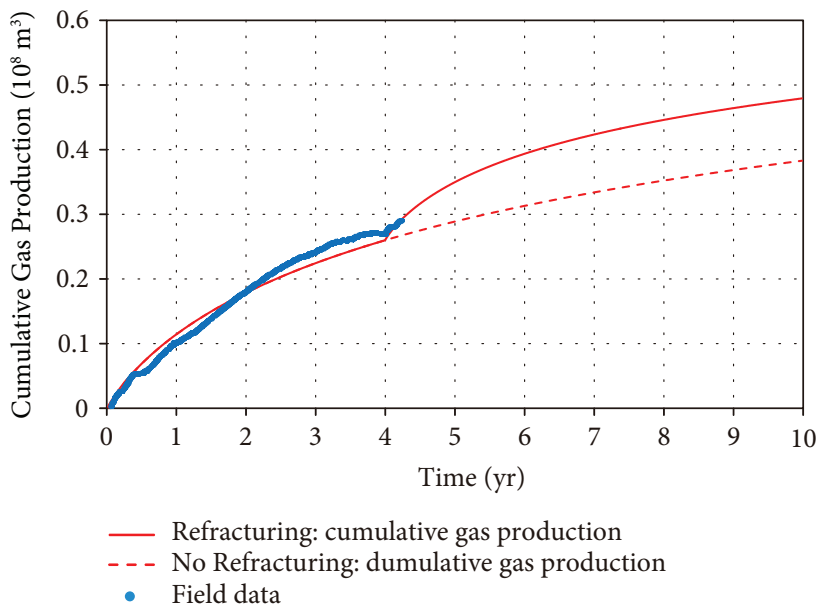

(b)

FIgURE 3: Comparison of simulation results with field data: (a) gas flow rate and (b) cumulative gas production.

how much of the lateral and which stage were stimulated $[27,28]$. Fortunately, the microseismic monitoring data proved that intervals closer to the heel (equivalent to stages 3 through 6 from the original stimulation treatment) were refractured.

For the refracturing work, the hydraulic fracture conductivity is promoted from $0.1 \mathrm{D} \bullet \mathrm{cm}$ to $0.4 \mathrm{D} \bullet \mathrm{cm}$; the reservoir pressure and the adsorption gas content distribution of the simulated reservoir with refracturing treatment are illustrated in Figures 2(a) and 2(b), respectively. Compared to the stage with restimulation, the reservoir pressure of stage 5 and stage 6 maintains a higher level after 10 years of production due to the depletion of fracture conductivity, the recovery of the absorbed gas is very low, and a large amount of absorbed gas still remains in the shale reservoir.

The gas production is increased through refracturing treatment, as shown in Figure 3. Figure 3(a) shows the field data of the gas flow rate for the horizontal well with initial fracturing treatment and refracturing treatment producing

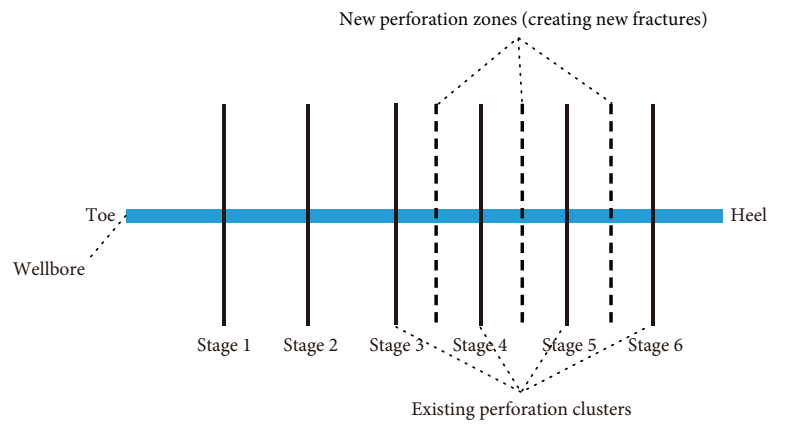

FIGURE 4: Different refracturing scenarios: refracturing through the existing perforation clusters and refracturing through new perforation zones.

at a constant well pressure. This well was shut in for 7 times before refracturing, which may be one of the main factors that lead to history data-matching error. In general, the simulation results present a good match with the field data, 


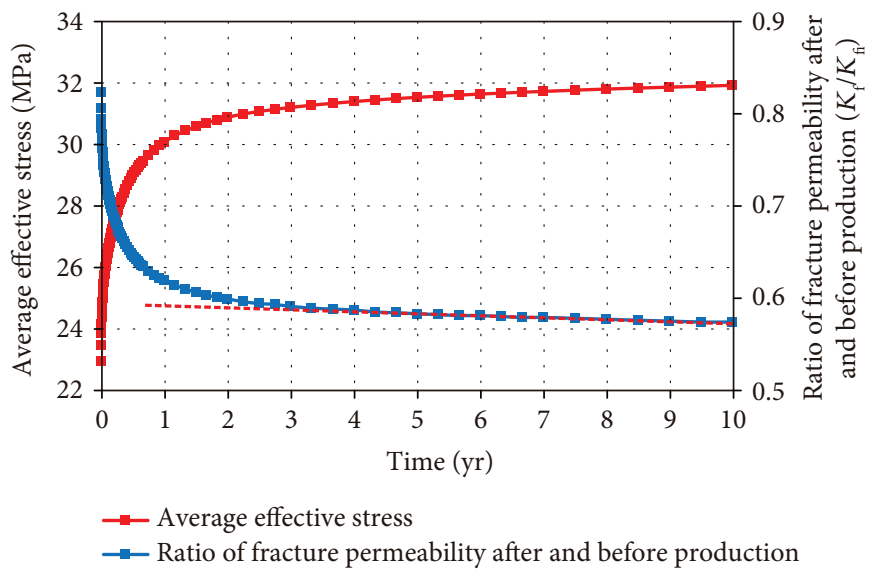

FIgURE 5: The variation of average effective stress at the well point grid and ratio of fracture permeability after and before production.

which has verified the numerical model is capable of modeling initial fracturing and refracturing of shale formation.

3.2. Parametric Study Hydraulic Fractures. The role that optimal refracturing time, hydraulic fracture permeability, and hydraulic fracture half-length play in gas production is explored in this section. Two cases are considered, as shown in Figure 4. In the first case, the refracturing job is performed through the existing perforation clusters. In the second case, the refracturing job is performed through new perforation zones. In addition, the pumping parameters are also discussed combined with sensitivity analysis.

3.2.1. The Optimal Refracturing Time. Finding the optimal time for refracturing is crucial so as to maximize the performance of the refracturing job; the flow capacity of hydraulic fracture and cumulative gas production are the important indicators. The effective stress will increase as the reservoir pressure depletes during the production, and the induced effective stress increment will lead to the degrading flow capacity of the hydraulic fracture, which is one of the major obstacles for expected shale gas recovery. As shown in Figure 5, during the early production stage, the ratio of the hydraulic fracture permeability after and before production $\left(K_{\mathrm{f}} / K_{\mathrm{fi}}\right)$ decreases sharply, and it presents a linear and stable decreasing trend after 3 years of production. The gas production performance is simulated for refracturing at the third, fourth, and fifth years, respectively. Cumulative gas production of 10 years is shown in Figure 6. As shown in the figure, refracturing at the fourth and the fifth years achieves almost the same cumulative gas production, while refracturing at the third year achieves a better performance but not obvious. However, there is an optimum time for refracturing, according to the research results of Wang et al., waiting too long between initial stimulation and refracturing results in reduced treatment effectiveness [29]. This is because the reservoir pressure continues to decrease while the fracture flow capacity presents a stable value. Therefore, it is the optimal time for a refracturing job when the flow capacity of the original fractures trends to be stable.

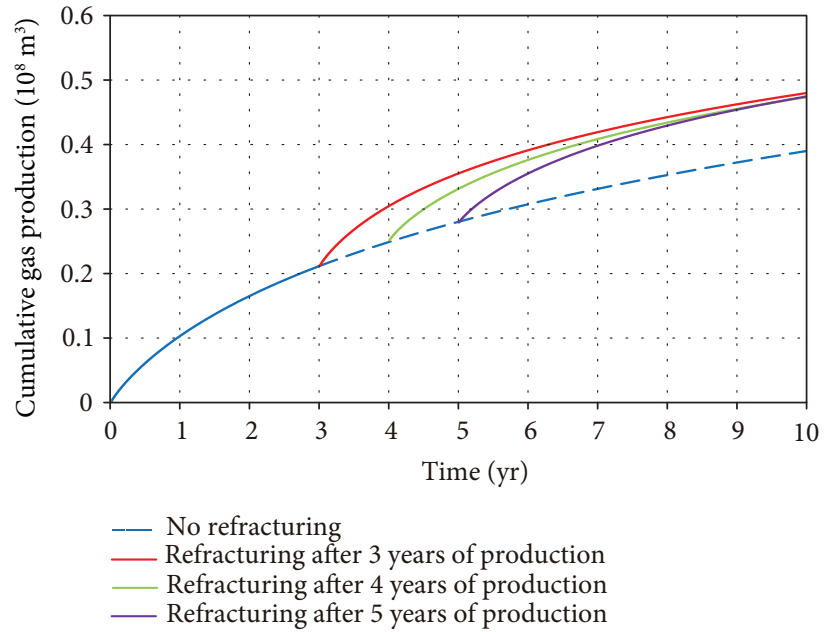

Figure 6: Cumulative gas production for different refracturing times.

For the horizontal shale gas well in Sichuan Basin, it is better to perform refracturing work after 3 years of production.

3.2.2. Hydraulic Fracture Conductivity. As shown in Figures 7 and 8 , the gas production of both refracturing scenarios presents a positive correlation with hydraulic fracture conductivity. Figures 7(a) and 8(a) illustrate that the gas flow rate of refracturing through the existing perforation clusters (4 stages) is higher than that of refracturing through new perforation zones (3 stages). However, refracturing through new perforation zones achieves better gas production compared to reopening of the original fractures for the consideration of every stage contribution. In the case of $0.4 \mathrm{D} \cdot \mathrm{cm}$ hydraulic fracture conductivity, the initial average gas flow rate of every stage for refracturing through existing perforation zones is $1.57 \times 10^{4} \mathrm{~m}^{3}$, while the average gas flow rate of every stage for refracturing through new perforation clusters is $1.79 \times 10^{4} \mathrm{~m}^{3}$. The average cumulative gas production of every stage for refracturing through new perforation zones is higher than that of refracturing through existing perforation clusters, as shown in Figures 7 (b) and 8(b). This is because the area undrained by the initial hydraulic fractures 


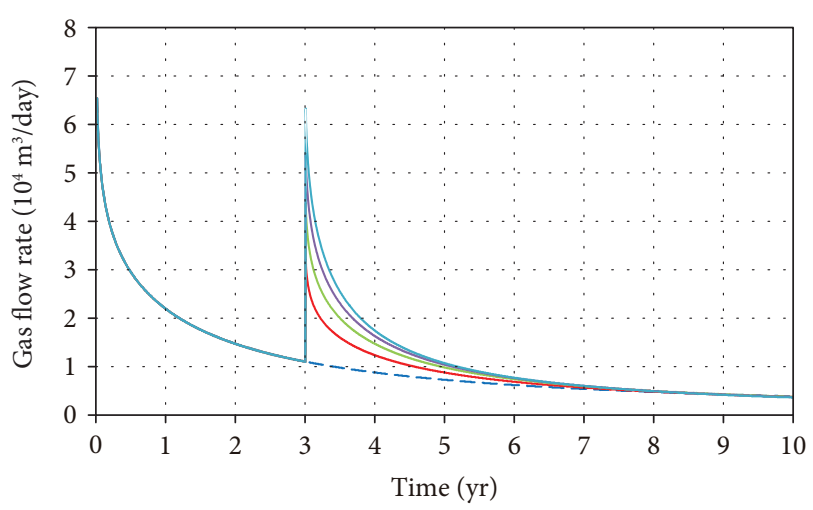

-- No refracturing: fracture conductivity $0.1 \mathrm{D} . \mathrm{cm}$
- Refracturing: fracture conductivity $0.1 \mathrm{D} . \mathrm{cm}$
- Refracturing: fracture conductivity $0.2 \mathrm{D} . \mathrm{cm}$
— Refracturing: fracture conductivity $0.3 \mathrm{D} . \mathrm{cm}$
— Refracturing: fracture conductivity $0.4 \mathrm{D} . \mathrm{cm}$

(a)

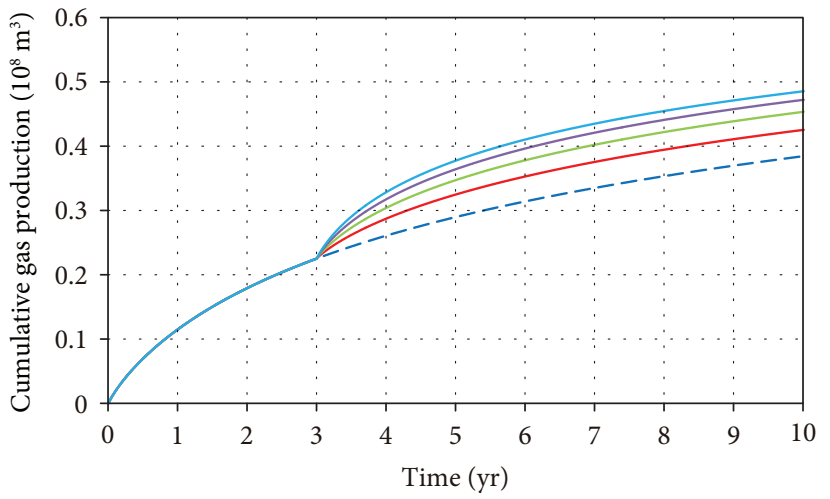

- - - No refracturing: fracture conductivity $0.1 \mathrm{D} . \mathrm{cm}$

— Refracturing: fracture conductivity $0.1 \mathrm{D} . \mathrm{cm}$

— Refracturing: fracture conductivity $0.2 \mathrm{D} . \mathrm{cm}$

— Refracturing: fracture conductivity 0.3 D.cm

— Refracturing: fracture conductivity 0.4 D.cm

(b)

FIGURE 7: Well performance of refracturing through existing perforation clusters: (a) gas flow rate and (b) cumulative gas production.

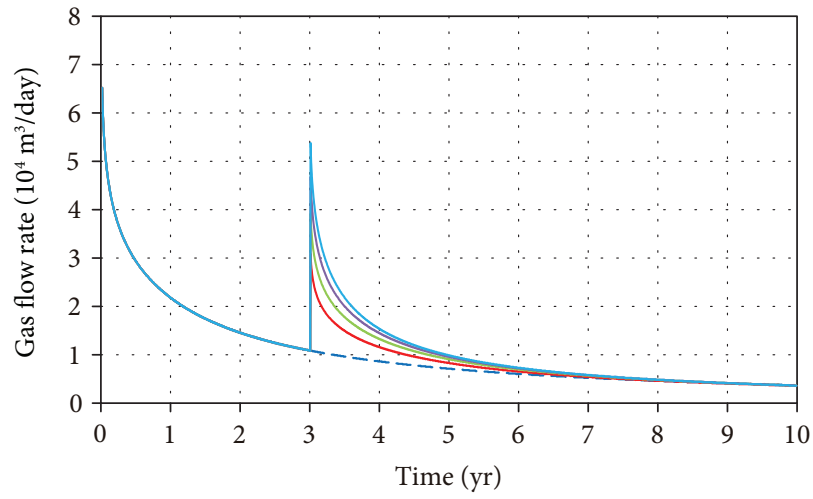

- - - No refracturing: fracture conductivity $0.1 \mathrm{D} . \mathrm{cm}$

— Refracturing: fracture conductivity 0.1 D.cm

— Refracturing: fracture conductivity 0.2 D.cm

— Refracturing: fracture conductivity 0.3 D.cm

— Refracturing: fracture conductivity 0.4 D.cm

(a)

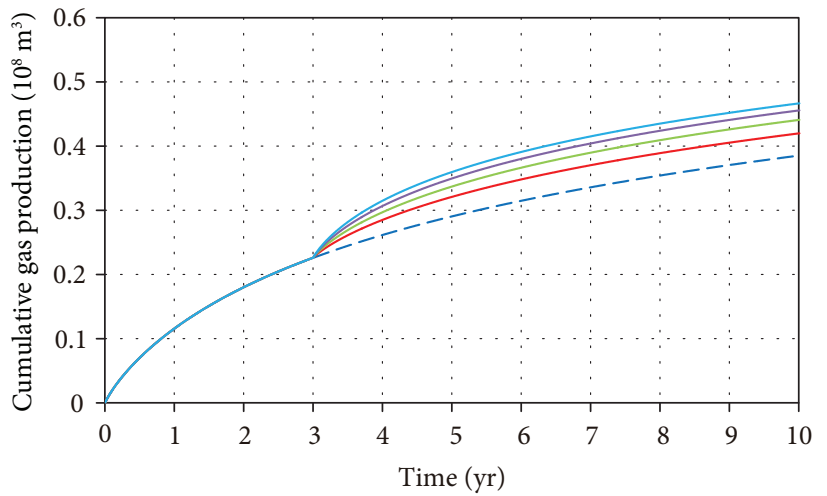

- - - No refracturing: fracture conductivity 0.1 D.cm

— Refracturing: fracture conductivity $0.1 \mathrm{D} . \mathrm{cm}$

— Refracturing: fracture conductivity $0.2 \mathrm{D} . \mathrm{cm}$

— Refracturing: fracture conductivity $0.3 \mathrm{D} . \mathrm{cm}$

— Refracturing: fracture conductivity 0.4 D.cm

(b)

FIGURE 8: Well performance of refracturing through new perforation zones: (a) gas flow rate and (b) cumulative gas production.

maintains relatively higher reservoir pressure, which contributes a higher production pressure drop. As shown in Figures 9 and 10, compared with performing refracturing through existing perforation clusters, refracturing through new perforation clusters can communicate the area which the initial fracturing is unstimulated, expanding the reservoir seepage area and improving the reservoir recovery. It is unlikely that economic success will be achieved simply by restoring the flow capacity of hydraulic fractures with new proppant. Therefore, higher proppant concentration and large-scale treatment size should be applied to increase fracture geometry and reservoir contact with the wellbore for both refracturing scenarios. In addition, refracturing with higher strength proppant is helpful for hydraulic fractures to maintain long-term conductivity due to the increment of effective stress [29], as shown in Figure 5.
3.2.3. Hydraulic Fracture Half-Length. In the case of refracturing through new perforation clusters, gas flow rate and cumulative gas production for different hydraulic fracture half-length are shown in Figures 11(a) and 11(b), respectively. Increasing the hydraulic fracture half-length enlarges the seepage area along the longitudinal direction of the reservoir as to promote gas production. As shown in Figure 11(b), the cumulative gas production of the well increases from $0.48 \times 10^{8} \mathrm{~m}^{3}$ to $0.54 \times 10^{8} \mathrm{~m}^{3}$ while the hydraulic fracture half-length increases from $70 \mathrm{~m}$ to $110 \mathrm{~m}$. In addition, the reservoir pressure decreases slower with higher hydraulic fracture half-length, which is beneficial for long-time production, as shown in Figures 12 and 13. However, in refracturing, the fracture does not follow the same path of the initial fracture due to the change in stress anisotropy; it is not easy to obtain longer fracture length [14]. 


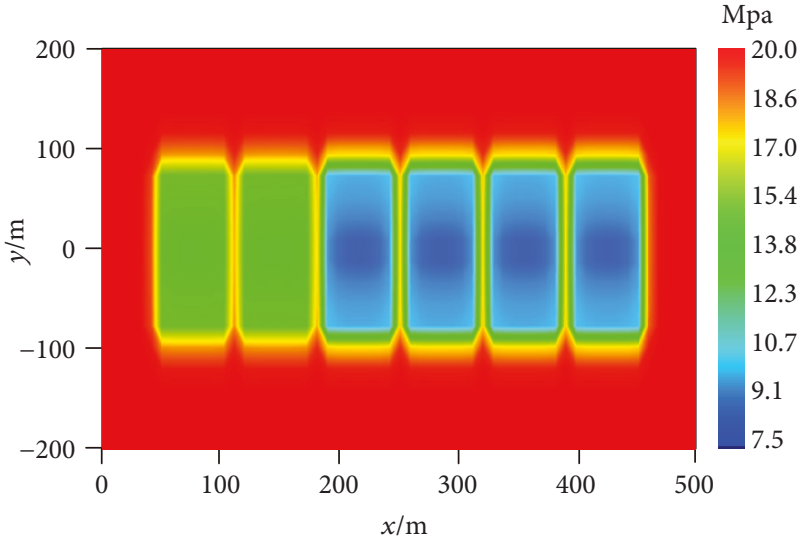

(a)

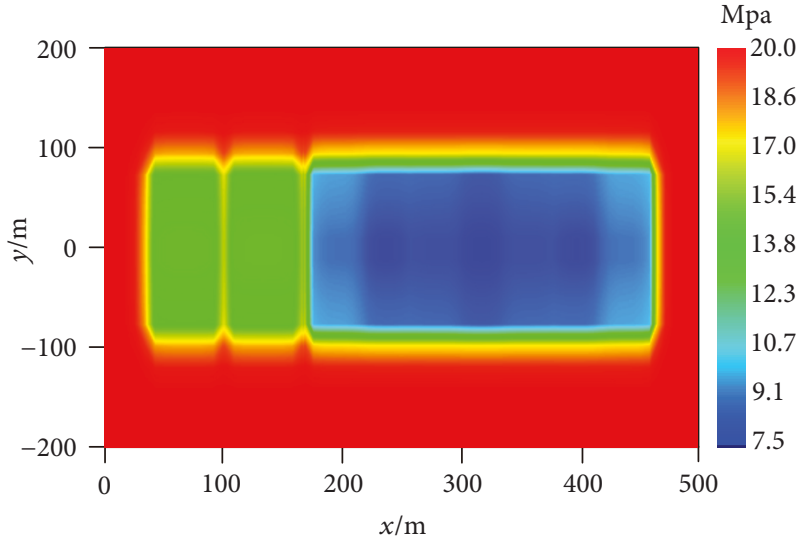

(b)

FIGURE 9: Reservoir pressure distribution: (a) refracturing through existing perforation clusters and (b) refracturing through new perforation zones.

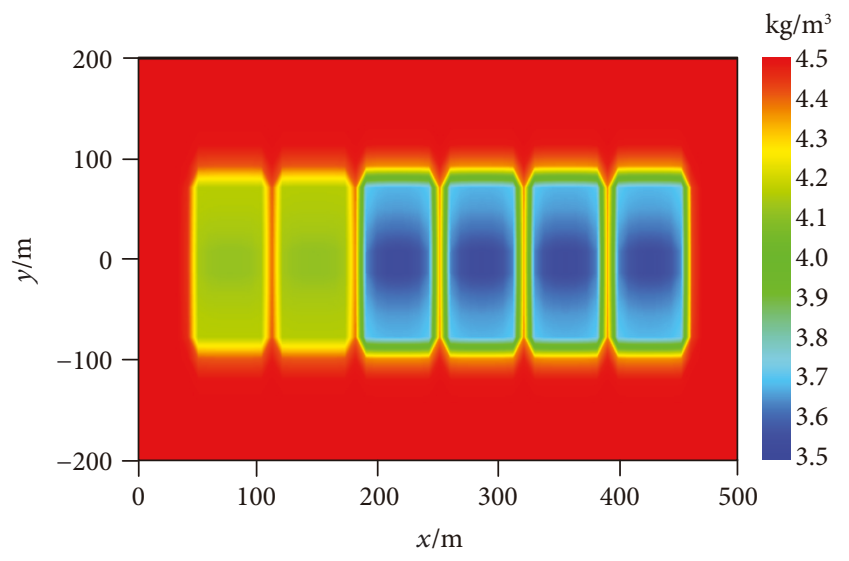

(a)

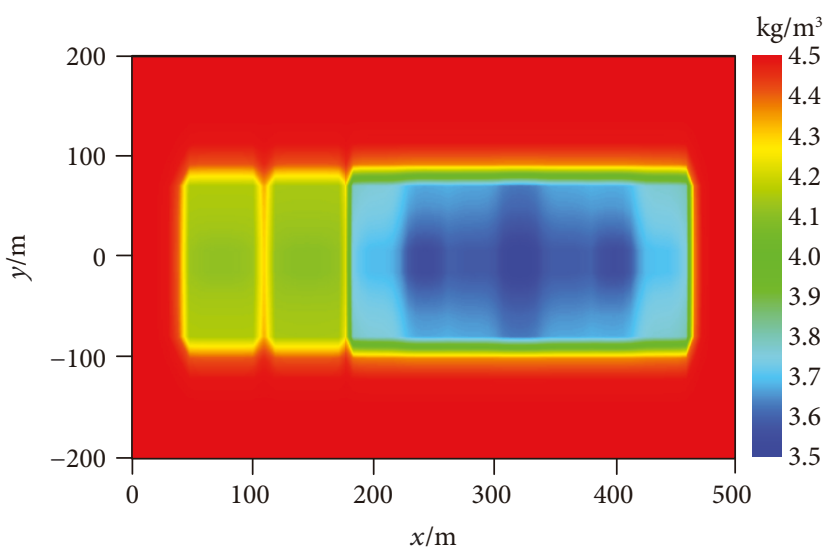

(b)

FIGURE 10: Reservoir adsorption gas content distribution: (a) refracturing through existing perforation clusters and (b) refracturing through new perforation zones.

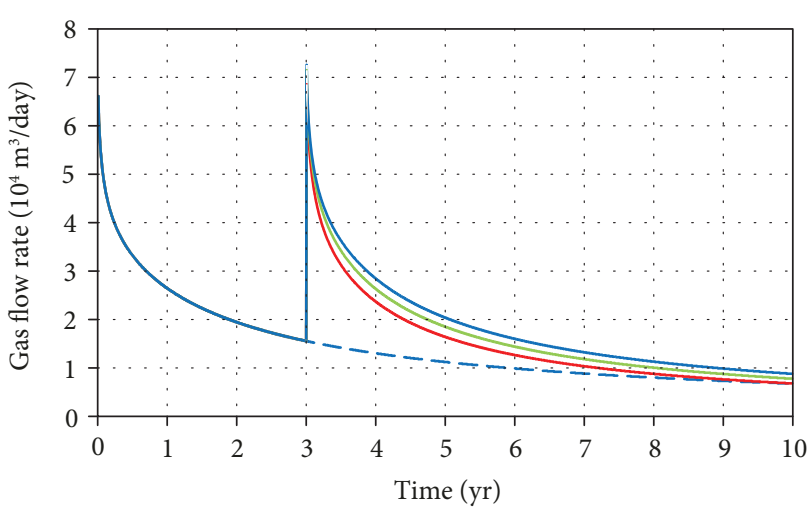

-- - No refracturing: fracture half-length $70 \mathrm{~m}$

- Refracturing: fracture half-length $70 \mathrm{~m}$

— Refracturing: fracture half-length $90 \mathrm{~m}$

— Refracturing: fracture half-length $110 \mathrm{~m}$

(a)

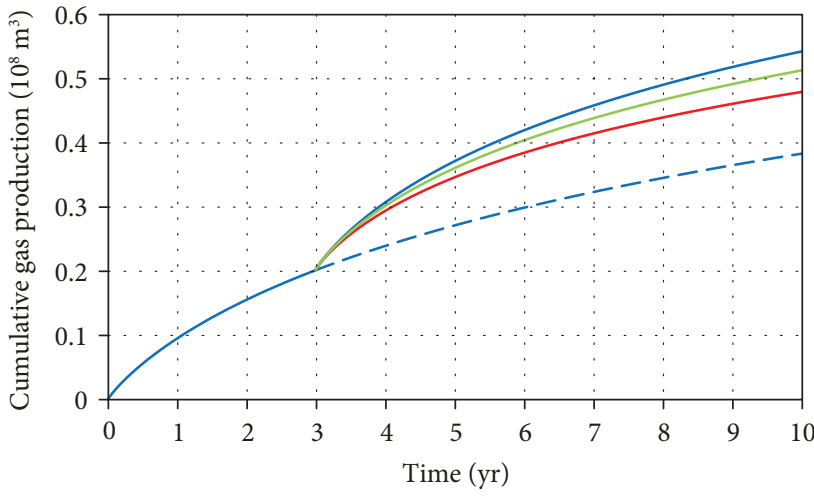

--- No refracturing: fracture half-length $70 \mathrm{~m}$

- Refracturing: fracture half-length $70 \mathrm{~m}$

— Refracturing: fracture half-length $90 \mathrm{~m}$

— Refracturing: fracture half-length $110 \mathrm{~m}$

(b)

FIGURE 11: Effects of hydraulic fracture half-length on: (a) gas flow rate and (b) gas flow rate of refracturing through new perforation zones. 


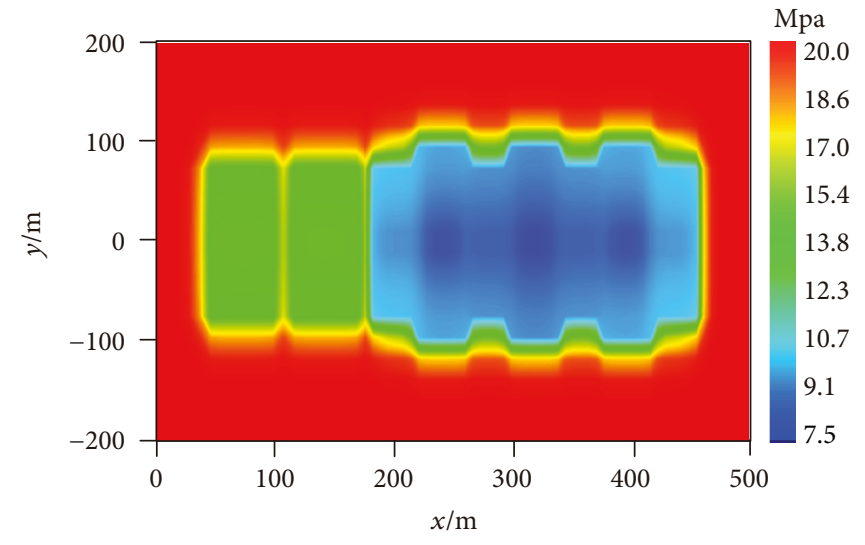

(a)

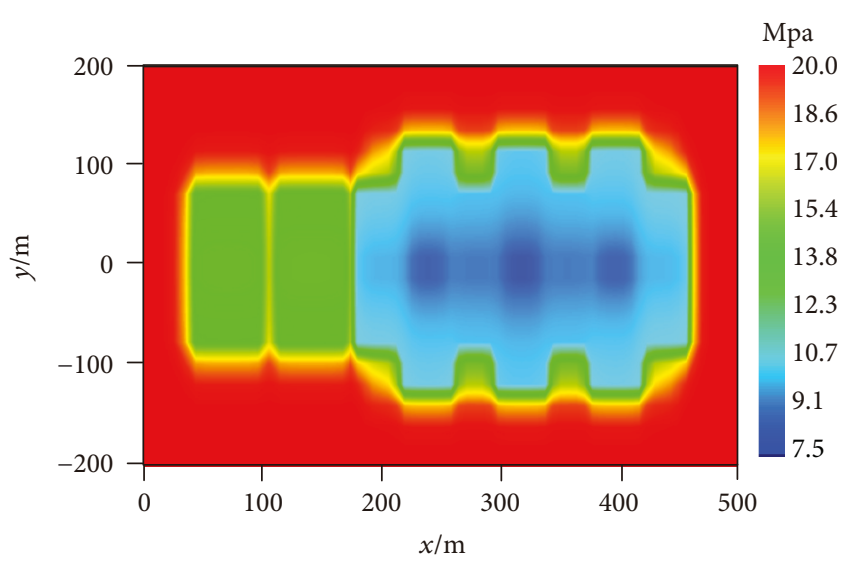

(b)

FIgURE 12: Reservoir pressure distribution: (a) $90 \mathrm{~m}$ hydraulic fracture half-length and (b) $110 \mathrm{~m}$ hydraulic fracture half-length.

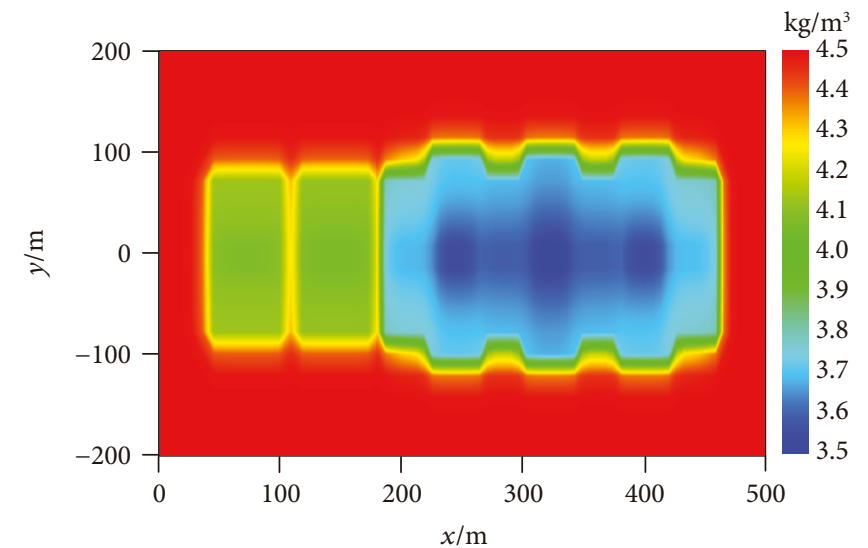

(a)

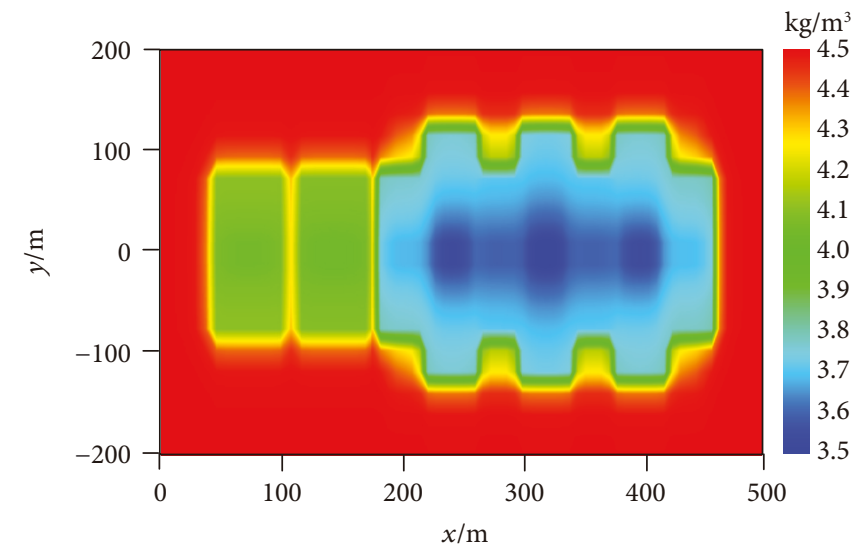

(b)

FIGURE 13: Reservoir adsorption gas content distribution: (a) $90 \mathrm{~m}$ hydraulic fracture half-length and (b) $110 \mathrm{~m}$ hydraulic fracture half-length.

3.2.4. Pumping Parameters. The pumping parameters of the refracturing job should be designed for enlarging fracture geometry, improving pay coverage, and restoring fracture conductivity. The existing fracture network should be taken into consideration. For the horizontal well discussed in this paper, the pumping rate of the initial fracturing job is $13 \sim 14 \mathrm{~m}^{3} / \mathrm{min}$, due to the existing fracture network and higher fracturing fluid filtration, and the pumping rate increased to $14 \sim 16 \mathrm{~m}^{3} / \mathrm{min}$. In addition, the average fluid volume of every stage increases from $1960 \mathrm{~m}^{3}$ to $2490 \mathrm{~m}^{3}$, as shown in Figure 14.

100 mesh, 40/70 mesh, and 30/50 mesh ceramic proppant are used for both initial fracturing and refracturing job; the portion of different size ceramic proppant used is shown in Figures 15 and 16. For initial fracturing, only an average volume of $7.5 \mathrm{~m}^{3} 100$ mesh proppant is used to polish the fracture near the wellbore for every stage treatment, 40/70 mesh proppant is mainly used to prop the hydraulic fracture, and an average volume of $9.6 \mathrm{~m}^{3} 30 / 50$ mesh proppant is used to achieve higher fracture conductivity near the wellbore. This well is generally refractured, and the higher proppant is delivered within the limitation of well head pressure (WHP).

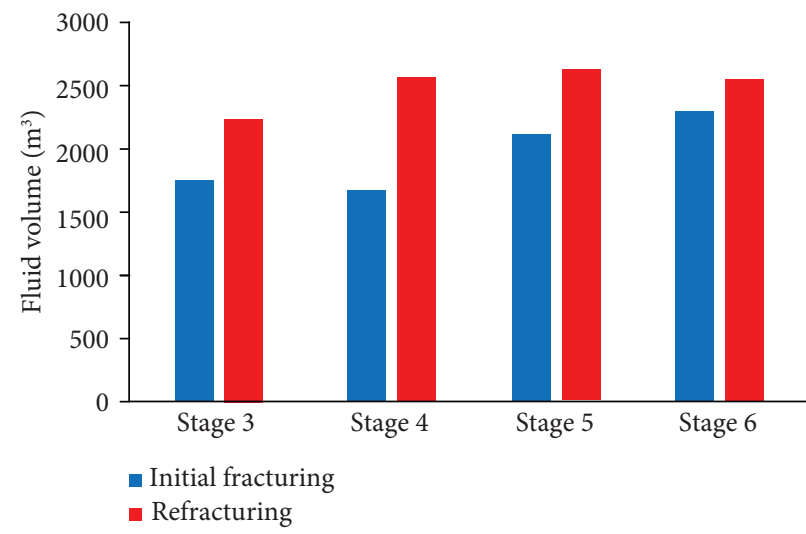

FIgURe 14: Comparison of the total fluid volume of the initial fracturing job and refracturing job.

Based on microseismic monitoring and pumping data statistics, the average volume of 100 mesh proppant is promoted from $7.5 \mathrm{~m}^{3}$ to $25 \mathrm{~m}^{3}$ to keep the narrow fractures created by refracturing open. $40 / 70$ mesh proppant is also the main proppant used to restore fracture conductivity. 


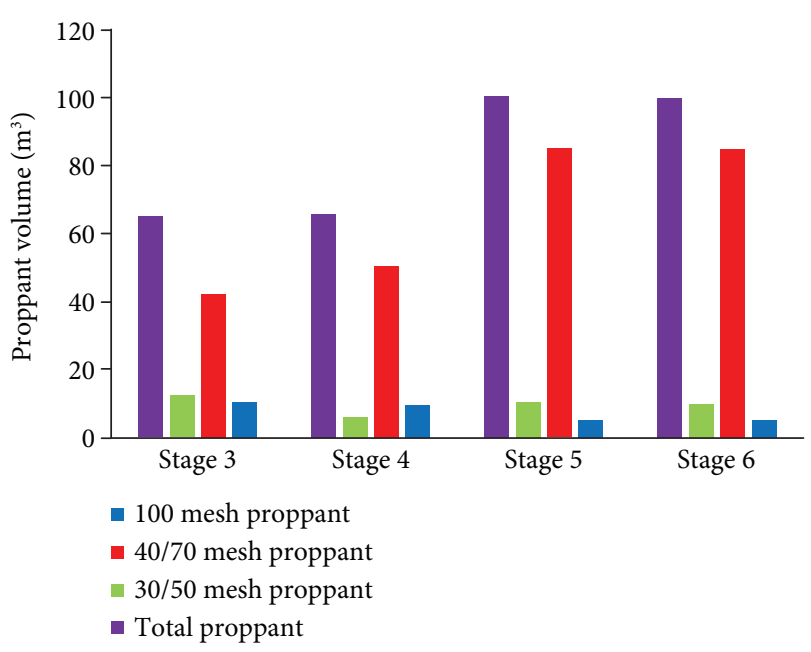

Figure 15: Proppant parameters of initial fracturing job.

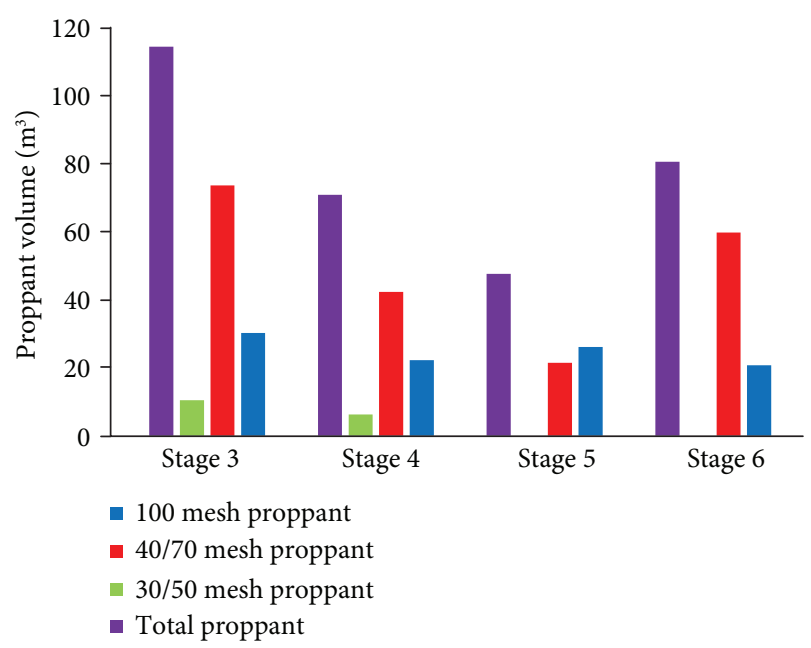

Figure 16: Proppant parameters of the refracturing job.

The field production data validate that the pumping parameters for the refracturing job performed through the existing clusters can effectively restore fracture conductivity as to promote gas flow rate (Figure 3). For refracturing through the existing clusters, a higher portion of microproppant is helpful to keep the narrow fractures created by refracturing open for improving gas production. It is the most common method to promote pumping rate, fluid volume, and proppant concentration in the previous successful refracturing jobs [29-32]. On the one hand, a higher pumping rate helps to reduce proppant collection at the bottom of the wellbore [6]. On the other hand, higher proppant concentration and large-scale treatment size are helpful to restore or increase hydraulic fracture conductivity so as to increase gas production, as shown in Figure 7.

\section{Conclusion}

A numerical model, considering the existing stimulated reservoir volume and multi-scale gas transport, is applied to simulate the gas production of the refractured shale well.
The model is verified against field data of the gas flow rate. The optimum time for refracturing is discussed based on the simulation results. Two refracturing scenarios: refracturing through existing perforation clusters and refracturing through new perforation zones, are included in the simulation work. The role that the hydraulic fracture conductivity and hydraulic fracture half-length play in gas production for different refracturing cases is explored, and the pumping parameters are also discussed. The main observations and conclusions are summarized below:

(1) The simulation results of the gas flow rate present a good match with the field data. It is the optimal time for the refracturing job when fracture flow capacity trends to be stable. For the horizontal shale gas well in Sichuan Basin, it is better to perform the refracturing job after 3 years of production.

(2) Production uplift can be achieved by performing the refracturing job both through existing perforation clusters and new perforation zones. Generally, creating new fractures can achieve better gas production compared to reopening the original fractures.

(3) The gas production presents a positive correlation with hydraulic fracture conductivity for both refracturing scenarios. It is unlikely that economic success will be achieved simply by restoring the flow capacity of hydraulic fractures with new proppant. Higher proppant concentration and large-scale treatment size should be applied to increase fracture geometry and reservoir contact with the wellbore.

(4) Increasing the hydraulic fracture half-length enlarges the seepage area along the longitudinal direction of the reservoir as to promote gas production. The reservoir pressure decreases slower with longer hydraulic fracture half-length, which is beneficial for long-time production.

(5) The field data validate that the pumping parameters for the refracturing job performed through the existing clusters can effectively restore fracture conductivity as to promote the gas flow rate.

\section{Nomenclature}

$C_{\mu s}: \quad$ Maximum monolayer adsorbed gas on the kerogen surface $\left(\mathrm{mol} / \mathrm{m}^{3}\right)$

$C_{\mathrm{k}}$ : The moles of free gas per kerogen organic pore

volume $\left(\mathrm{mol} / \mathrm{m}^{3}\right)$

$C_{\mathrm{m}}$ : The moles of free gas per inorganic matrix pore volume $\left(\mathrm{mol} / \mathrm{m}^{3}\right)$

$C_{\mathrm{g}}: \quad$ Gas compression coefficient of inorganic matrix system $\left(\mathrm{MPa}^{-1}\right)$

$c_{\xi}: \quad$ Experimental coefficient

$D_{\text {kk }}: \quad$ Knudsen diffusivity of kerogen system $\left(\mathrm{m}^{2} / \mathrm{s}\right)$

$D_{\mathrm{km}}$ : Knudsen diffusivity of inorganic matrix system $\left(\mathrm{m}^{2} / \mathrm{s}\right)$

$D_{\mathrm{s}}: \quad$ Surface diffusion coefficient $\left(\mathrm{m}^{2} / \mathrm{s}\right)$ 
$F_{\mathrm{m}}: \quad$ Slippage factor

$G$ : $\quad$ Shear modulus (MPa)

$K_{\mathrm{k} 0}: \quad$ Kerogen intrinsic permeability $\left(\mu \mathrm{m}^{2}\right)$

$K_{\text {mapp }}$ : Apparent inorganic matrix permeability $\left(\mu \mathrm{m}^{2}\right)$

$K_{\xi}: \quad$ Permeability of shale reservoir during production $\left(\mu \mathrm{m}^{2}\right)$

$K_{\xi_{0}}$ : Initial permeability of shale reservoir $\left(\mu \mathrm{m}^{2}\right)$

$R_{\mathrm{g}}: \quad$ Universal gas constant $(\mathrm{J} /(\mathrm{K} \bullet \mathrm{mol}))$

$r_{\mathrm{m}}$ : $\quad$ Pore radius of inorganic matrix $(\mathrm{m})$

$M_{\mathrm{g}}: \quad$ Molecular mass $(\mathrm{kg} / \mathrm{mol})$

$P_{\mathrm{k}}: \quad$ Kerogen pressure $(\mathrm{MPa})$

$P_{\mathrm{m}}: \quad$ Inorganic matrix pressure $(\mathrm{MPa})$

$P_{\mathrm{f}}: \quad$ Fracture pressure $(\mathrm{MPa})$

$P_{\mathrm{L}}: \quad$ Langmuir pressure $(\mathrm{MPa})$

$P_{\mathrm{i}}$ : Initial reservoir pressure $(\mathrm{MPa})$

$V_{\mathrm{L}}: \quad$ Langmuir volume $\left(\mathrm{m}^{3} / \mathrm{kg}\right)$

$V_{\text {std }}: \quad$ Gas molar volume at the standard condition $(273.15 \mathrm{~K}$ and $101.325 \mathrm{kPa})\left(\mathrm{m}^{3} / \mathrm{mol}\right)$

$Z$ : $\quad$ Deviation factor

$L_{\mathrm{f} x}, L_{\mathrm{f} y}$ : Fracture spacing of $x$-axis and $y$-axis, respectively $(\mathrm{m})$

$W_{\mathrm{mf}}$ : Mass transfer term between inorganic matter and natural fractures $\left(\mathrm{mol} /\left(\mathrm{m}^{3} \bullet \mathrm{s}\right)\right)$

$Q_{\text {gwell }}$ : Production rate of fracture system $\left(\mathrm{mol} /\left(\mathrm{m}^{3} \bullet \mathrm{s}\right)\right)$.

\section{Greek Symbols}

$\alpha_{\mathrm{m}}$ : Inorganic matrix effective stress coefficient

$\alpha_{\mathrm{k}}$ : Kerogen effective stress coefficient

$\alpha_{\mathrm{f}}$ : $\quad$ Fracture effective stress coefficient

$\sigma_{i j}^{\prime}: \quad$ Reservoir effective stress ( $\left.\mathrm{MPa}\right)$

$\sigma_{i j}: \quad$ Stress tensor $(\mathrm{MPa})$

$\sigma_{0}^{\prime}: \quad$ Initial effective stress $(\mathrm{MPa})$

$\sigma^{\prime}$ : $\quad$ Effective stress during production $(\mathrm{MPa})$

$\sigma_{\mathrm{km}}:$ Transient shape factor $\left(1 / \mathrm{m}^{2}\right)$

$\sigma_{\mathrm{mf}}$ : Pseudo-steady state shape factor $\left(1 / \mathrm{m}^{2}\right)$

$\varepsilon_{v}: \quad$ Volume strain

$\varepsilon_{\mathrm{S}}: \quad$ Volume strain induced by gas desorption

$\varepsilon_{\mathrm{kp}}$ : Portion of kerogen pore volume in total interconnected matrix pore volume

$\varepsilon_{\mathrm{ks}}$ : Portion of kerogen grain volume in total shale core grain volume

$\phi_{\xi}: \quad$ Porosity during production process

$\phi_{\xi 0}:$ Initial porosity

$\phi$ : Total matrix porosity

$\phi_{\mathrm{m}}:$ Inorganic matrix porosity

$\phi_{\mathrm{f}}$ : Fracture porosity

$\rho_{\mathrm{g}}: \quad$ Gas density $\left(\mathrm{kg} / \mathrm{m}^{3}\right)$

$\mu_{\mathrm{g}}: \quad$ Gas viscosity $(\mathrm{mPa} \bullet \mathrm{s})$

$\lambda: \quad$ Melanie constant

$u$ : Displacement $(\mathrm{m})$

$\delta_{i j}$ : The symbol of Kroneker (if $i=j$, then $\delta_{i j}=1$, else $\left.\delta_{i j}=0\right)$.

\section{Subscripts}

$\mathrm{k}$ : Related to kerogen $\mathrm{m}$ : Related to inorganic matrix

$\mathrm{f}$ : Related to fracture

0 : The reference state.

\section{Data Availability}

The basic data in this research article mainly come from the published works and a refractured horizontal shale well in Sichuan Basin, Southwest of China. The production data and pumping parameters of the refractured well are currently under embargo while the research findings are commercialized. Requests for data, 12 months after the publication of this article, will be considered by the corresponding author.

\section{Conflicts of Interest}

The authors declare that they have no conflicts of interest.

\section{Acknowledgments}

The authors would like to acknowledge the support of the Major Program of the National Natural Science Foundation of China (51490653) and the National Science and Technology Major Project of the Ministry of Science and Technology of China (2016ZX05023005-001-002).

\section{References}

[1] T. Jacobs, "Renewing mature shale wells through refracturing," Journal of Petroleum Technology, vol. 66, no. 4, pp. 52-60, 2014.

[2] L. P. Moore and H. Ramakrishnan, "Restimulation: candidate selection methodologies and treatment optimization," in SPE Annual Technical Conference and Exhibition, San Antonio, TX, USA, January 2006.

[3] M. C. Vincent, "Refracs: why do they work, and why do they fail in 100 published field studies?," in SPE Annual Technical Conference and Exhibition, Florence, Italy, January 2010.

[4] S. French, J. Rodgerson, and C. Feik, "Re-fracturing horizontal shale wells: case history of a Woodford Shale pilot project," in SPE Hydraulic Fracturing Technology Conference, The Woodlands, TX, USA, February 2014Society of Petroleum Engineers.

[5] B. Grieser, J. Calvin, and J. Dulin, "Lessons learned: Refracs from 1980 to present," in SPE Hydraulic Fracturing Technology Conference, The Woodlands, TX, USA, February 2016.

[6] G. J. Lindsay, D. J. White, G. A. Miller, J. D. Baihly, and B. Sinosic, "Understanding the applicability and economic viability of refracturing horizontal wells in unconventional plays," in SPE Hydraulic Fracturing Technology Conference, The Woodlands, TX, USA, February 2016.

[7] R. Malpani, S. Sinha, L. Charry, B. Sinosic, B. Clark, and K. Gakhar, "Improving hydrocarbon recovery of horizontal shale wells through refracturing," in SPE/CSUR Unconventional Resources Conference, Calgary, AB, Canada, October 2015.

[8] G. Rodvelt, M. Ahmad, and A. Blake, "Refracturing early Marcellus producers accesses additional gas," in SPE Eastern Regional Meeting, Morgantown, WV, USA, October 2015. 
[9] J. T. Krenger, J. Fraser, A. J. Gibson, A. Whitsett, J. Melcher, and S. Persac, "Refracturing design for underperforming unconventional horizontal reservoirs," in SPE Eastern Regional Meeting, Morgantown, WV, USA, October 2015.

[10] B. T. Hlidek, D. Potts, and A. Quinlan, "Cost effective monitoring and visualization system used for real-time monitoring of downhole operations from the wellhead," in SPE Annual Technical Conference and Exhibition, Dubai, UAE, September 2016.

[11] S. Tavassoli, W. Yu, F. Javadpour, and K. Sepehrnoori, "Well screen and optimal time of refracturing: a Barnett shale well," Journal of Petroleum Engineering, vol. 2013, Article ID 817293, 10 pages, 2013.

[12] P. Indras and C. Blankenship, "A commercial evaluation of refracturing horizontal shale wells," in SPE Annual Technical Conference and Exhibition, Houston, TX, USA, September 2015.

[13] L. Charry, R. Malpani, and B. Clark, "A step change in the learning curve for refracturing in the eagle ford," in Proceedings of the 4th Unconventional Resources Technology Conference, pp. 2807-2817, San Antonio, TX, USA, 2016.

[14] A. Morales, K. Zhang, K. Gakhar et al., "Advanced modeling of interwell fracturing interference: an eagle ford shale oil study refracturing," in SPE Hydraulic Fracturing Technology Conference, The Woodlands, TX, USA, February 2016.

[15] G. Miller, G. Lindsay, J. Baihly, and T. Xu, "Parent well refracturing: economic safety nets in an uneconomic market," in SPE Low Perm Symposium, Denver, CO, USA, May 2016.

[16] M. Haddad, A. Sanaei, E. W. Al-Shalabi, and K. Sepehrnoori, "Major obstacles in production from hydraulically refractured shale formations: reservoir pressure depletion and pore blockage by the fracturing fluid," in Unconventional Resources Technology Conference, pp. 2209-2218, San Antonio, TX, USA, 2015.

[17] E. Urban, D. Orozco, A. Fragoso, K. Selvan, and R. Aguilera, "Refracturing vs. infill drilling - a cost effective approach to enhancing recovery in shale reservoirs," in Unconventional Resources Technology Conference, pp. 2934-2953, San Antonio, TX, USA, 2016.

[18] J. Huang, C. Yang, X. Xue, and A. Datta-Gupta, "Simulation of coupled fracture propagation and well performance under different refracturing designs in shale reservoirs," in SPE Low Perm Symposium, Denver, CO, USA, May 2016.

[19] T. Huang, X. Guo, and F. Chen, "Modeling transient flow behavior of a multiscale triple porosity model for shale gas reservoirs," Journal of Natural Gas Science and Engineering, vol. 23, pp. 33-46, 2015.

[20] M. Zhang, J. Yao, H. Sun et al., "Triple-continuum modeling of shale gas reservoirs considering the effect of kerogen," Journal of Natural Gas Science and Engineering, vol. 24, pp. 252-263, 2015.

[21] A. Agharazi and S. Kashikar, "A geomechanical study of refracturing based on microseismic observations - case study of Haynesville and eagle ford wells," in Unconventional Resources Technology Conference, pp. 714-732, San Antonio, TX, USA, 2016.

[22] G. Sang, D. Elsworth, X. Miao, X. Mao, and J. Wang, "Numerical study of a stress dependent triple porosity model for shale gas reservoirs accommodating gas diffusion in kerogen," Journal of Natural Gas Science and Engineering, vol. 32, pp. 423438, 2016.
[23] D. Elsworth and M. Bai, "Flow-deformation response of dualporosity media," Journal of Geotechnical Engineering, vol. 118, no. 1, pp. 107-124, 1992.

[24] T. H. Kim, J. H. Lee, and K. S. Lee, "Integrated reservoir flow and geomechanical model to generate type curves for pressure transient responses of a hydraulically-fractured well in shale gas reservoirs," Journal of Petroleum Science and Engineering, vol. 146, pp. 457-472, 2016.

[25] H. Kazemi, L. S. Merrill Jr, K. L. Porterfield, and P. R. Zeman, "Numerical simulation of water-oil flow in naturally fractured reservoirs," Society of Petroleum Engineers Journal, vol. 16, no. 6, pp. 317-326, 1976.

[26] H. Sun, A. Chawathe, H. Hoteit, X. Shi, and L. Li, "Understanding shale gas production mechanisms through reservoir simulation," in SPE/EAGE European Unconventional Resources Conference and Exhibition, Vienna, Austria, February 2014.

[27] T. Xu, G. Lindsay, J. Baihly, R. Malpani, E. Ejofodomi, and D. Shan, "Unique multidisciplinary approach to model and optimize pad Refracturing in the Haynesville Shale," in Unconventional Resources Technology Conference, pp. 3289-3303, Austin, TX, USA, July 2017.

[28] T. Xu, G. Lindsay, J. Baihly, E. Ejofodomi, R. Malpani, and D. Shan, "Proposed refracturing methodology in the Haynesville Shale," in SPE Annual Technical Conference and Exhibition, San Antonio, TX, USA, October 2017.

[29] S. Y. Wang, X. L. Luo, and R. S. Hurt, "What we learned from a study of re-fracturing in Barnett shale: an investigation of completion/fracturing, and production of re-fractured wells," in International Petroleum Technology Conference, Beijing, China, March 2013.

[30] M. Diakhate, A. Gazawi, R. D. Barree et al., "Refracturing on horizontal wells in the Eagle Ford Shale in South Texas - one operator's perspective," in SPE Hydraulic Fracturing Technology Conference, The Woodlands, TX, USA, February 2015.

[31] L. He and W. Wenjun, "Performance of refracturing in multiple thin layers of low permeability oilfields," in International Petroleum Technology Conference, Beijing, China, March 2013.

[32] D. B. Allison, S. S. Curry, and B. L. Todd, "Restimulation of wells using biodegradable particulates as temporary diverting agents," in Canadian Unconventional Resources Conference, Calgary, AB, Canada, January 2011. 

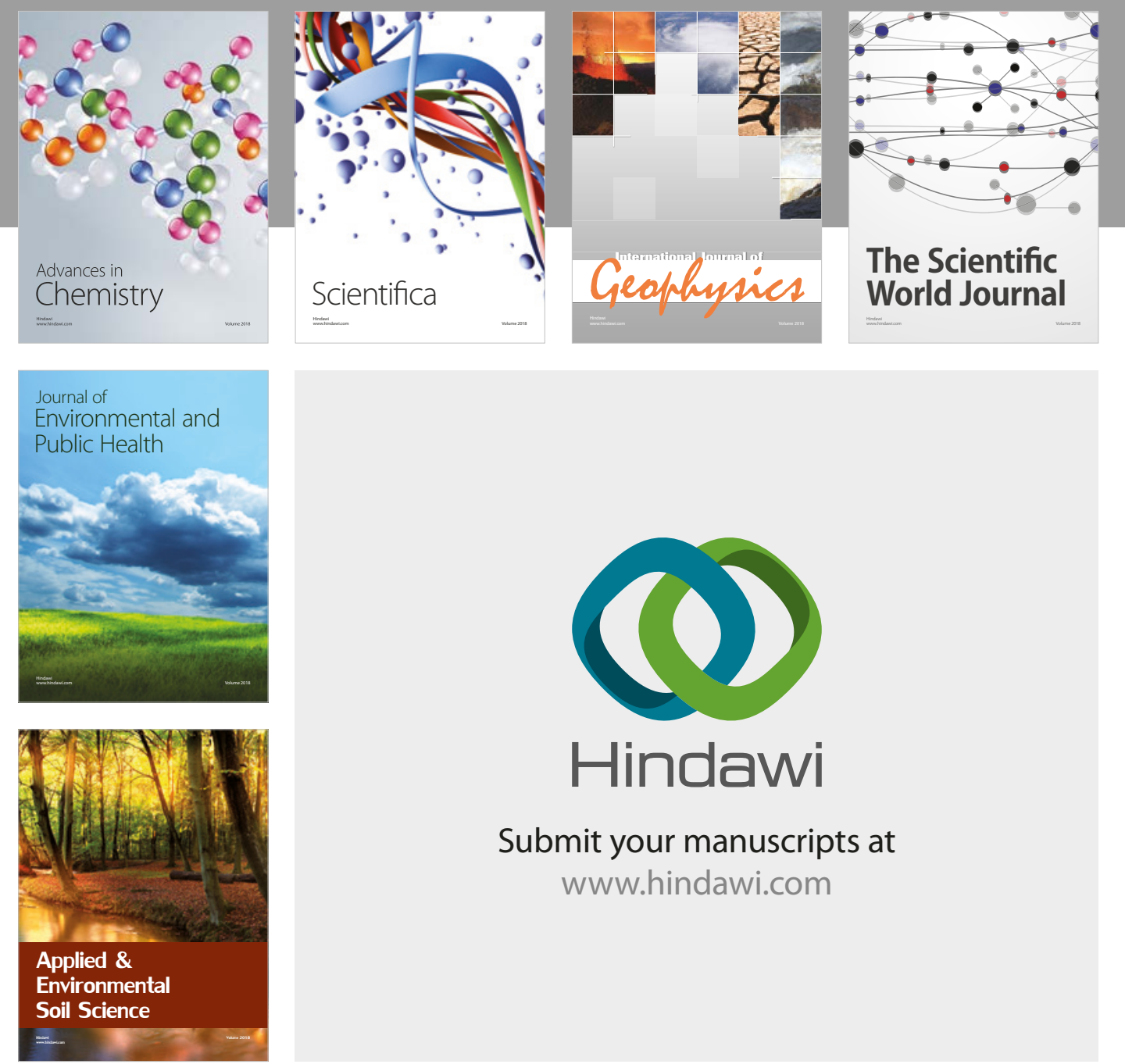

The Scientific

\section{World Journal}
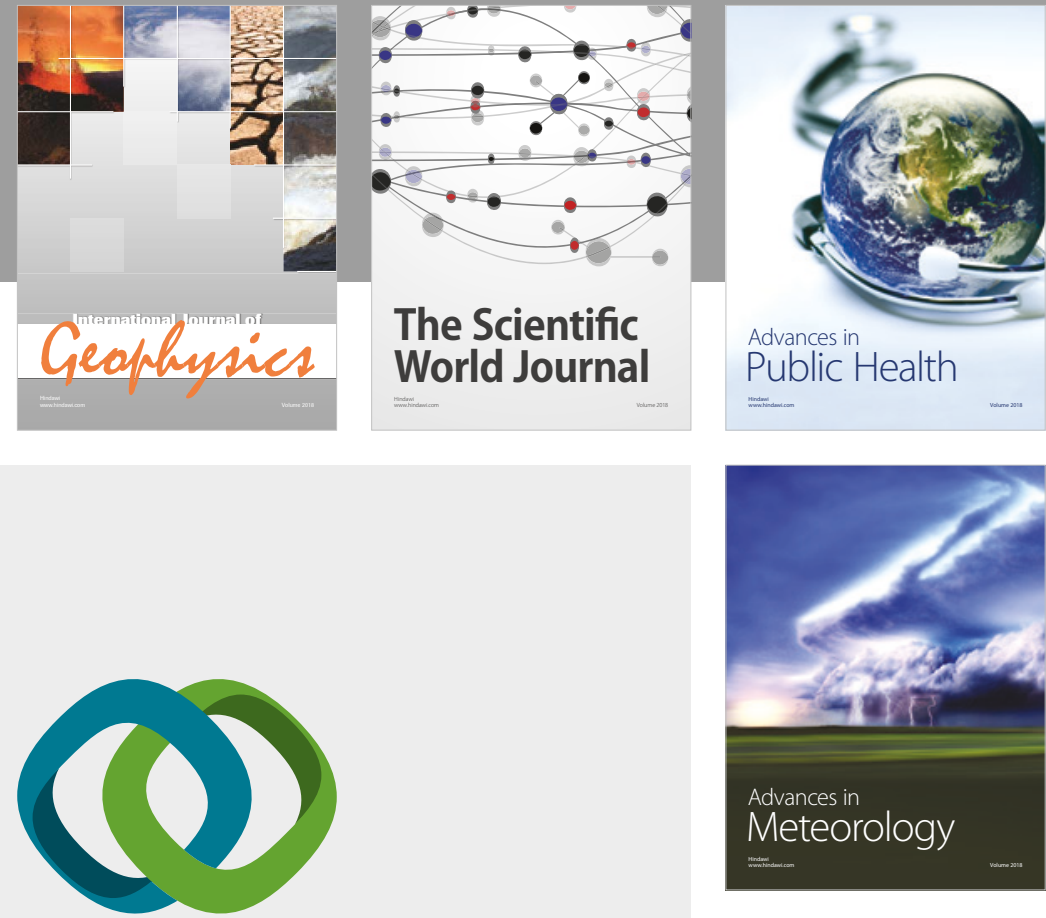

Advan

Public Health

\section{Hindawi}

Submit your manuscripts at

www.hindawi.com
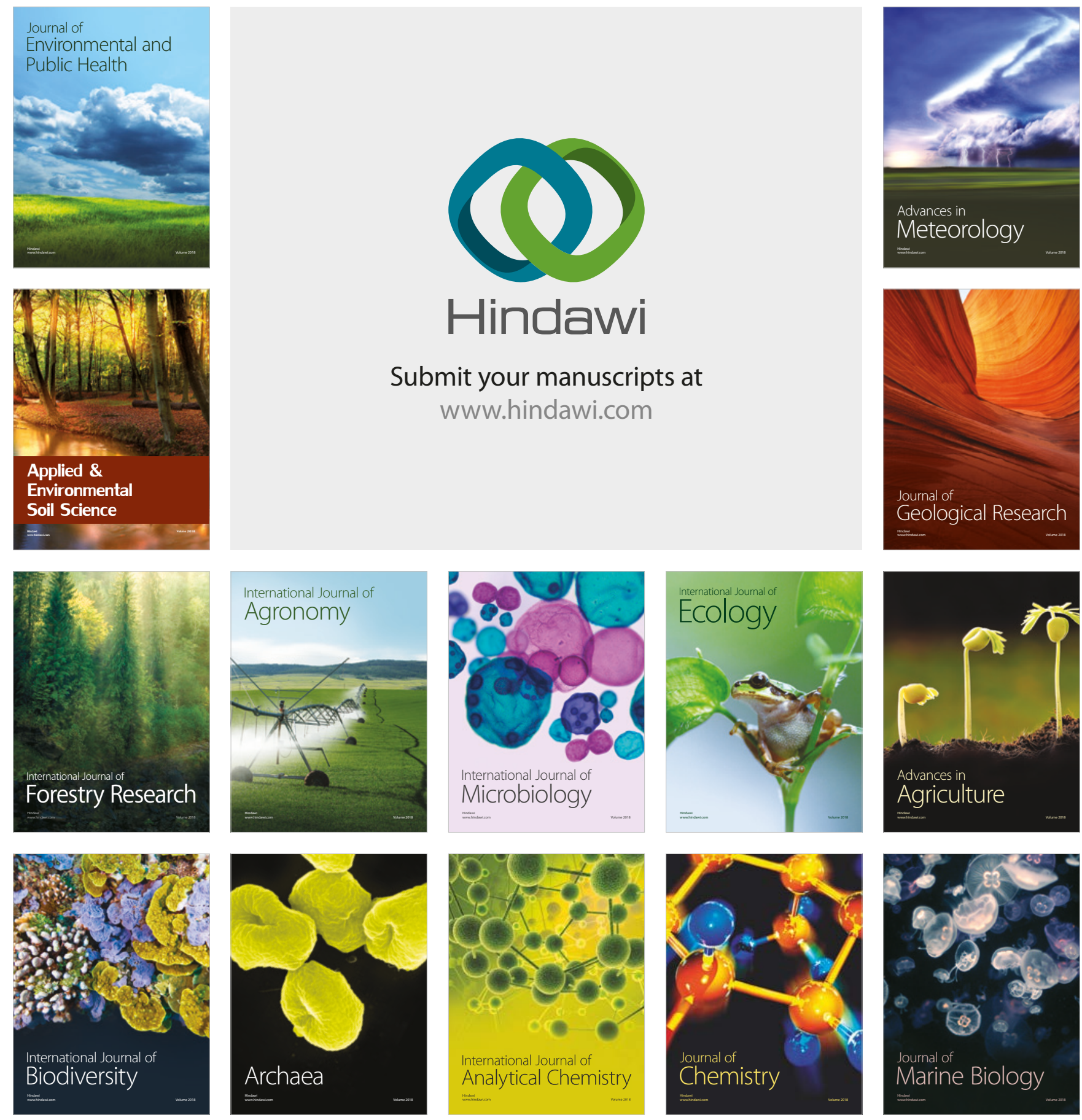